\title{
Neuronally expressed stem cell factor induces neural stem cell migration to areas of brain injury
}

\author{
Lixin Sun, Jeongwu Lee, and Howard A. Fine \\ Neuro-Oncology Branch, National Cancer Institute, National Institutes of Neurological Disorder and Stroke, NIH, Bethesda, Maryland, USA.
}

\begin{abstract}
Neural stem/progenitor cell (NSPC) migration toward sites of damaged central nervous system (CNS) tissue may represent an adaptive response for the purpose of limiting and/or repairing damage. Little is known of the mechanisms responsible for this migratory response. We constructed a cDNA library of injured mouse forebrain using subtractive suppression hybridization (SSH) to identify genes that were selectively upregulated in the injured hemisphere. We demonstrate that stem cell factor (SCF) mRNA and protein are highly induced in neurons within the zone of injured brain. Additionally, the SCF receptor c-kit is expressed on NSPCs in vitro and in vivo. Finally, we demonstrate that recombinant SCF induces potent NSPC migration in vitro and in vivo through the activation of c-kit on NSPCs. These data suggest that the SCF/c-kit pathway is involved in the migration of NSPCs to sites of brain injury and that SCF may prove useful for inducing progenitor cell recruitment to specific areas of the CNS for cell-based therapeutic strategies.
\end{abstract}

\section{Introduction}

Neural stem/progenitor cell (NSPC) migration is an essential process for the development of the central nervous system (CNS) as well as the ongoing neurogenesis that occurs in the mature CNS of most vertebrate species, including mammals (1-3). It has been demonstrated that NSPCs proliferate in the subventricular zone (SVZ) and migrate tangentially through the SVZ, in a pattern reminiscent of the rostral migratory stream (RMS), toward the olfactory bulb where they differentiate into mature neurons (4-6). It has also been recently demonstrated that NSPCs migrate to sites of pathological insult such as various types of brain injury (i.e., ischemia and blunt trauma) and tumors (7-12). NSPC migration toward damaged CNS tissue may represent an adaptive response for the purpose of limiting and/or repairing damage, although to date there are few data to definitively support or refute this hypothesis. Regardless of their physiological role in injury, the migratory properties of NSPCs could theoretically be exploited for cell-based therapeutics $(13,14)$. Thus, the microenvironmental conditions and guidance signals that regulate NSPC migration in the adult need to be elucidated.

Although little is understood about the mechanism controlling NSPC migration in the adult CNS, several key mechanisms responsible for NSPC migration in embryonic development have been elucidated. Embryonic NSPCs recognize cues provided by cells along the path of migration and are guided at long distances by gradients of chemoattractant molecules that are released selectively by cells along the way and at their final destination (15-17). The discovery of netrins (18-21), semaphorins (22-24),

Nonstandard abbreviations used: glial fibrillary acidic protein (GFAP); microtubule-associated protein 2 (MAP2); neural stem/progenitor cell (NSPC); paraformaldehyde (PFA); phosphoinositide-3 kinase (PI-3Kinase); recombinant mouse SCF (rmSCF); ricinus communis agglutinin I (RCA I); rostral migratory stream (RMS); stem cell factor (SCF); subtractive suppression hybridization (SSH); subventricular zone (SVZ); $\beta$-tubulin type III (TUJ-1).

Conflict of interest: The authors have declared that no conflict of interest exists.

Citation for this article: J. Clin. Invest. 113:1364-1374 (2004).

doi:10.1172/JCI200420001. ephrins $(25,26)$, and Slit proteins (27-29) established the existence of neuronal migration guidance signals at long distances by diffusible secreted proteins that have NSPC chemoattractant and repulsive properties. Recently it has been suggested that certain cytokines with known important functions in CNS development (i.e., transforming growth factor $\alpha, b F G F$, and EGF) were capable of enhancing ischemia-induced progenitor proliferation and migration $(30,31)$. Nevertheless, our understanding of the mechanisms guiding neural progenitor cell migration in pathological states remains limited. Identification of diffusible NSPC chemoattractant factors would not only help to better understand the totality of mechanisms responsible for injury-mediated NSPC migration but also could have significant therapeutic implications for the prospect of cell-based therapeutic strategies for injury repair.

In an attempt to identify NSPC chemoattractant molecules in injured brain tissue, we utilized subtractive cDNA suppression hybridization (SSH) to identify genes that were selectively upregulated during injury. We then utilized an in vitro NSPC migration assay to screen the products of our isolated cDNA clones for NSPC chemotactic activity. We now report the identification of stem cell factor (SCF) as a cytokine that is highly overexpressed by neurons at sites of brain injury. We additionally show that the SCF receptor (c-kit) is expressed on NSPCs and is autophosphorylated following ligand binding and that SCF mediates potent chemoattractant activity for NSPCs both in vitro and in vivo.

\section{Methods}

Animals and "freeze" injury. All mice (NCI-Frederick, Frederick, Maryland, USA) were handled following Institutional guidelines (National Institutes of Health ethics guidelines for use of animals in research). Stereotactic surgery was performed with SCID male mice (6-8 weeks of age) sedated by anesthesia (ketamine and xylazine at doses of $80 \mathrm{mg} / \mathrm{kg}$ body weight and $10 \mathrm{mg} / \mathrm{kg}$ body weight, respectively, by intraperitoneal administration). As schematically illustrated in the Figure $1 \mathrm{~A}$, the skull was opened $1 \mathrm{~mm}$ anterior to the bregma and $2.5 \mathrm{~mm}$ lateral to the midline with 
a dental drill, leaving the dura intact. The "freeze" brain injury was produced by insertion of a Hamilton syringe precooled in liquid nitrogen through a cranial hole to a depth of $2 \mathrm{~mm}$ below the dural surface. The needle was kept in this position for $30 \mathrm{sec}-$ onds. This procedure was repeated five times in each animal. The animal's body temperature was kept within physiological range during and after the surgery. The animals were euthanized at 5 days after injury by $\mathrm{CO}_{2}$ inhalation and their brains were rapidly dissected on an ice-cold board. The dorsal forebrain ipsilateral and contralateral to the site of injury was rapidly dissected out (illustrated in Figure 1A) and stored at $-70^{\circ} \mathrm{C}$ for RNA extraction. The entire dorsal forebrain from animals with bilateral injury was collected for Western blot and the Boyden chamber migration assay. In these studies, the corresponding brain areas from naive animals were used as controls.

Cell culture. Human NSPCs (Clonetics, Walkersville, Maryland, USA) and mouse NSPCs isolated from the forebrains of embryos at day 14.5 of gestation were cultured in neural basal medium supplemented with B27 (Invitrogen Corp., Carlsbad, California, USA), 20 $\mathrm{ng} / \mathrm{ml}$ of bFGF and $20 \mathrm{ng} / \mathrm{ml}$ of EGF (R\&D Systems, Minneapolis, Minnesota, USA), $0.5 \mu \mathrm{M}$ glutamine, and appropriate antibiotics, as described previously (32). The cells grew in a six-well plate as nonadherent cells and were prevented from attaching to the plates by periodic gentle agitation of the plates each day. EGF and bFGF were added every other day and culture medium was changed weekly until neurospheres became visible. The spheres were passaged by enzymatic and mechanical dissociation every 7-10 days and were reseeded as single cells into growth medium at a density of about 100,000 cells $/ \mathrm{ml}$. The cells that adhered to the plastic and began to extend processes were removed from the wells and were not cultured in subsequent passages. U-87, a cell line derived from a malignant glioma, and NIH 3T3 were purchased from American Type Culture Collection (Manassas, Virginia, USA) and were cultured in the conditions recommended by the company.

Boyden chamber assay. The effects of SCF on NSPC migration were determined by a modified Boyden chamber assay as described previously (33). A 96-well cell migration kit was utilized (Chemicon, Temecula, California, USA), and each well was separated into two chambers by a membrane with $8-\mu \mathrm{m}$ pores. The cells were briefly trypsinized and were adjusted to a density of $4 \times 10^{5}$ cells $/ \mathrm{ml}$ in a 1:20 dilution of B27 medium without growth factors. Some cells were pretreated with a c-kit-blocking antibody (ACK45; PharMingen, San Diego, California, USA) for 30 minutes at room temperature. Migration of NIH 3 T3 cell was also assayed as a control.
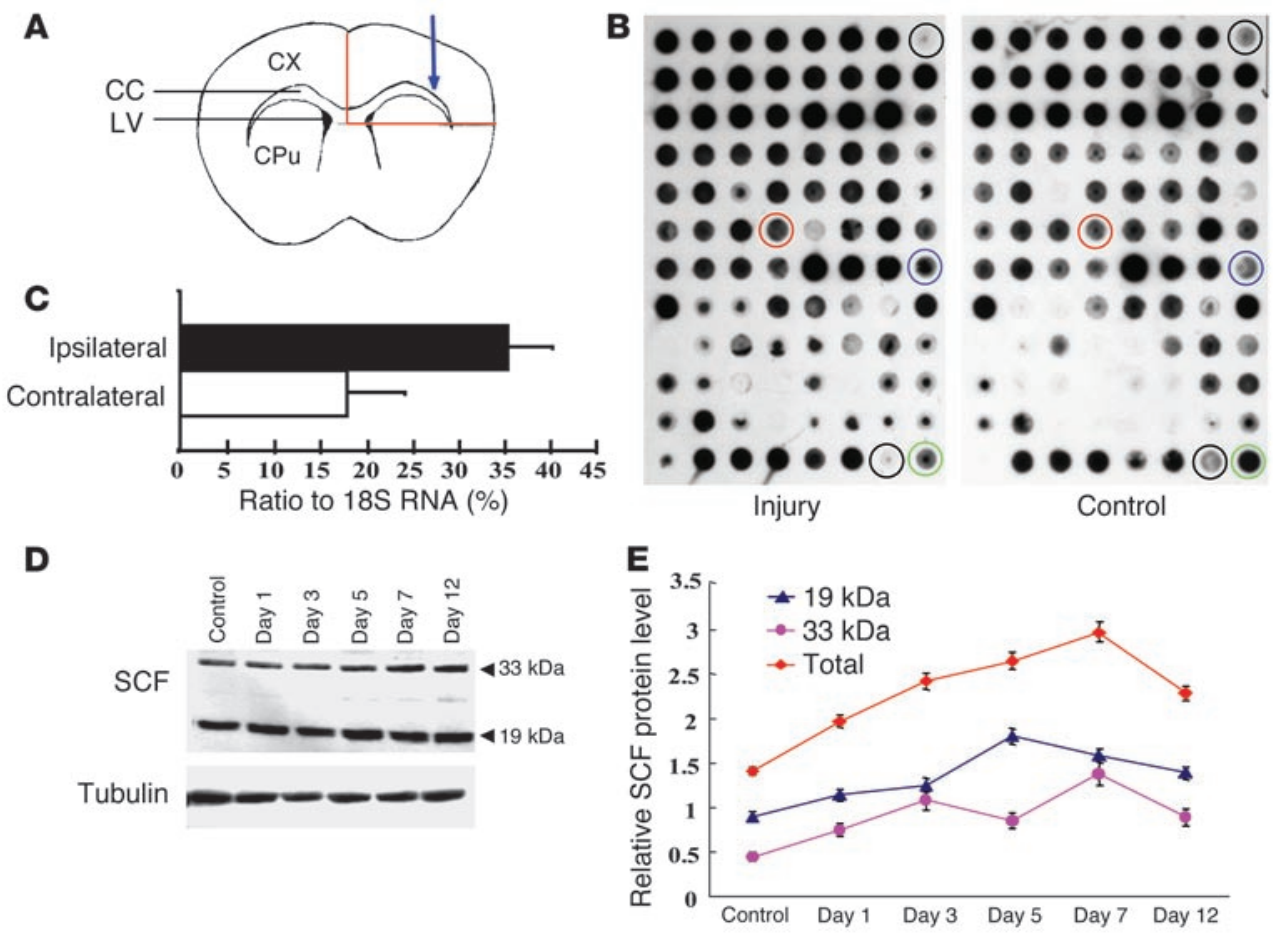

\section{Figure 1}

SCF induced by "freeze" injury to the brain. (A) Schematic illustration of "freeze" injury. Blue arrow indicates the insertion track of the precooled needle. Red lines separate the forebrain into injured and uninjured hemispheres and divide the hemispheres into its dorsal and ventral halves. CX, cortex; CPu, caudate putamen (striatum); CC, corpus callosum; LV, lateral ventricle. (B) Custom microarray confirms increased SCF message in the injured brain at day 5. The cDNA clones from SSH library were loaded individually onto duplicate nitrocellulose filters, one hybridized by the injured brain-derived cDNAs (Injury) and another hybridized by contralateral control (Control). Membranes with the SCF gene are shown, and the SCF spots are marked with red and blue circles. Actin and GAPDH are shown as green and black circles, respectively. SCF images are stronger in the injured brain-derived cDNA-hybridized blot than the control. (C) Quantitative RT-PCR. Fold induction of SCF mRNA in "freeze"-injured forebrain 5 days after injury compared with the uninjured contralateral side $(P<0.05)$. The SCF mRNAs were individually normalized to levels of 18S RNA. (D) Time-dependent changes in SCF protein induction after "freeze" brain injury, as measured by Western blot, using uninjured forebrain as a control. Two major bands were present, representing the transmembrane form of SCF (33 kDa) and the cleaved, soluble form of SCF (19 kDa). (E) Quantification of SCF expression by computer densitometry. The band intensities of SCF were normalized to those of $\beta$-tubulin. 
Recombinant mouse SCF (rmSCF) (R\&D Systems) was dissolved in the same medium and adjusted to the various concentrations. After different concentrations of SCF or brain tissue lysates were added to the lower chamber as attractants, $100 \mu$ l of the NSPCs $\left(4 \times 10^{4}\right)$ was applied to the upper chamber on the top of membrane. A group of control chambers without rmSCF was also included. After 4 hours of incubation at $37^{\circ} \mathrm{C}$, the migratory cells on the bottom of the insert membrane were dissociated from the membrane by incubation with cell detachment buffer. These cells were subsequently lysed and stained with CyQuant GR dye (Chemicon), which exhibits strong fluorescence enhancement when bound to cellular nucleic acids, and fluorescence was measured with a fluorescence plate reader with a 480/520-nm filter set.

SSH library. Total RNA was isolated from either the injured or contralateral dorsal forebrain from 60 mice using Trizol (Invitrogen Corp.) and was purified with an RNeasy kit (Qiagen, Valencia, California, USA). The poly(A) RNA was subsequently isolated from purified total RNA with a poly(A) RNA isolation kit (Qiagen). Complementary DNA (cDNA) was synthesized from 2 $\mu \mathrm{g}$ poly(A) RNA using the SMART PCR cDNA Synthesis Kit and subtractive hybridization was performed with the CLONTECH PCR-Select cDNA Subtraction Kit (BD Biosciences, Palo Alto, California, USA) based on the protocols suggested by the company. The "tester" cDNA came from injured brain, whereas the "driver" pool was from uninjured forebrain. After adaptor ligation, the "tester" cDNA pool was then hybridized with "driver" cDNAs at a ratio of 1:20 for selection of transcripts specifically upregulated in the injured hemisphere. After hybridization, suppression PCR using primers specific for the "tester" PCR adaptors selectively amplified differentially expressed transcripts for 15 cycles. The amplified cDNAs were subsequently cloned into the T/A cloning vector PGEM-T Easy (Promega, Madison, Wisconsin, USA), and about 500 colonies were obtained in total.

Custom cDNA microarray. To confirm that the cDNA clones of the SSH library contained the upregulated transcripts induced by the injury, custom cDNA microarrays were constructed and used to screen the library. First, individual colonies from the SSH library were grown overnight at $37^{\circ} \mathrm{C}$ in Luria broth medium containing $50 \mu \mathrm{g} / \mathrm{ml}$ of ampicillin. After the plasmids were isolated, the inserts were cut out with the EcoRI restriction enzyme and were analyzed by electrophoresis on a $1 \%$ agarose gel. Inserts within the clones ( $~ 85 \%$ of total) were then amplified by PCR. The PCR products were then "dot-blotted" onto GeneScreen Plus hybridization transfer membranes (Perkin Elmer Life Sciences Inc., Boston, Massachusetts, USA) in duplicate with the S\&S Minifold I Dot-Blot System (Schleicher \& Schuell, Dassel, Germany). In addition to the SSH library clones, each blot also contained actin and GAPDH as controls. The cDNA targets were then labeled and hybridized to the filter. The poly(A) RNA from brain 5 days after injury and uninjured brain was "reverse-transcribed" into cDNA and was amplified for 10 cycles with the SMART PCR cDNA Synthesis Kit as described above. Purified cDNA probes (100 ng per blot) were labeled with fluorescence by the random primer method using the Gene Images Random Prime Labelling and Detection System (Amersham Pharmacia Biotech, Piscataway, New Jersey, USA). Each duplicated membrane was hybridized with the injured or uninjured brain-derived probes at $60^{\circ} \mathrm{C}$ overnight. The subsequent washing and antibody-mediated detection was identical to the protocol recommended by the company. Finally, the hybridized membranes were laid next to each other, exposed to Kodak x-ray film (Eastman Kodak Co., Rochester, New York, USA), and developed simultaneously.

DNA sequencing and sequence analysis. Our custom cDNA microarray screen confirmed the presence of over 300 overexpressed clones in the SSH library. These clones were then sequenced using the ABI PRISM Dye Terminator Cycle Sequencing Ready Reaction kit (Perkin Elmer Life Sciences) with the T7 promoter primer on an ABI 373 automated sequencer (Applied Biosystems, Foster City, California, USA). Database homology searches for the cDNA sequence and deduced protein sequences were performed by a basic local alignment search tool program using the DNA and expressed sequence tag DNA databases at the National Center for Biotechnology Information (http://www.ncbi.nih.gov/BLAST). From the 300 clones, 196 unique genes were identified as being upregulated in the injured area of the forebrain.

RT-PCR and real-time PCR. The reverse transcription reaction and PCR were performed as described previously (34). The $c$-kit primers for mouse were 5'-CCATGTGGCTAAAGATGAAC-3' (upstream) and $5^{\prime}$-ACTGCTGGTGCTCGGGTTTG-3' (downstream), and for human were 5'-TATACAACCCTGGCATTATGTCC-3' (upstream) and 5'-TGCGAAGGAGGCTAAACCTA-3' (downstream). For realtime RT-PCR analysis, $S C F$ probes were selected in the connecting region of two exons ( $5^{\prime}$-ACTCTAGCGTGTAAATC- 3 '); the upstream primer was $5^{\prime}$-GAAGTCAGTCTTTTCCCTTGACAGT$3^{\prime}$ and the downstream primer was 5'-GCATGTCACATTATACTATTGCAAACA-3'. Real-time PCR was performed with the ABI PRISM 7900 HT Sequence Detection System (Applied Biosystems) in triplicate and data were analyzed on the basis of threshold cycle values of each sample and were normalized with 18S RNA.

Immunoprecipitation and immunoblot. Injured dorsal forebrains were dissected 24 hours, 3 days, 5 days, 7 days and 12 days after injury and were homogenized in a lysis buffer containing $50 \mathrm{mM}$ Tris- $\mathrm{HCl}(\mathrm{pH}$ 8.0), $120 \mathrm{mM} \mathrm{NaCl}, 0.5 \% \mathrm{NP}-40$, and Protease Inhibitor Cocktail (Roche, Indianapolis, Indiana, USA). Brain tissue was kept on ice for 30 minutes and supernatants were collected after centrifugation. The brain lysates were separated by $4-12 \%$ polyacrylamide gel electrophoresis (Invitrogen Corp.) and were transferred to membranes. The filters were blotted with rabbit polyclonal anti-SCF (1:50 dilution; Chemicon). The NSPCs were treated with $100 \mathrm{ng} / \mathrm{ml}$ of $\mathrm{rmSCF}$ or were left untreated for 10 minutes and then were washed with ice-cold PBS. Some mouse NSPCs were treated with rat monoclonal c-kit-blocking antibody (ACK45; PharMingen) for 30 minutes at room temperature before SCF stimulation. The NSPCs were resuspended in a protease inhibitor mixture containing radioimmunoprecipitation assay buffer ( $1 \% \mathrm{NP}-40,0.5 \%$ sodium deoxycholate, $0.1 \%$ SDS, $0.1 \mathrm{mg} / \mathrm{ml} \mathrm{PMSF}$, and $0.1 \mathrm{mM} \mathrm{NaVO}_{4}$ in PBS). The cell lysates were precleared with protein A-Sepharose (Amersham Pharmacia Biotech), incubated with rabbit polyclonal antibody against c-kit (clone H-300; Santa Cruz Biotechnology, Santa Cruz, California, USA), and collected on protein A-Sepharose beads. After being washed and eluted, the immunoprecipitates were separated by electrophoresis through 7\% polyacrylamide gels. After transfer, filters were hybridized with anti-phosphotyrosine (1:1,000 dilution; clone PY99; Santa Cruz Biotechnology) and visualized with a peroxidase-conjugated secondary antibody. After detection of SCF or a phosphotyrosine within c-kit, the membranes were stripped and reblotted with $\beta$-tubulin antibody (Santa Cruz Biotechnology) or with anti-c-kit (H-300; Santa Cruz Biotechnology).

Immunocytochemistry. Cells and brain sections were processed for immunocytochemistry as described previously (35). Briefly, brains 
were fixed in $4 \%$ phosphate-buffered paraformaldehyde (PFA) after transcardial perfusion and were processed as paraffin sections or floating sections. For paraffin sections, brains were embedded in paraplast and cut into coronal sections $10 \mu \mathrm{m}$ in thickness on a rotary microtome. After being deparaffinized, the sections were processed for immunohistochemistry. For floating sections, perfused brains were soaked in $30 \%$ sucrose overnight, frozen in isopentane cooled by dry ice, and cut on a cryostat into sections $30 \mu \mathrm{m}$ in thickness. NSPCs were cultured on laminin-coated glass wells and were fixed in 4\% PFA for 20 minutes at room temperature. Cells and brain sections were processed for immunohistochemistry using the following primary antibodies: rat monoclonal anti-BrdU (1:50 dilution; Accurate Chemical, Westbury, New York, USA); rabbit polyclonal anti-SCF (1:100 dilution; Chemicon), and mouse monoclonal anti-nestin (1:400 dilution; Chemicon); mouse monoclonal anti-glial fibrillary acidic protein (anti-GFAP) (1:400 dilution; Sigma-Aldrich, St. Louis, Missouri, USA), mouse monoclonal anti-microtubule-associated proteins 2 (anti-MAP2) (1:1,000 dilution; SigmaAldrich); rat monoclonal anti-CD13 (1:100 dilution; BD PharMingen); rabbit polyclonal anti-c-kit (1:100 dilution; H-300; Santa Cruz Biotechnology); mouse monoclonal anti- $\beta$-tubulin type III (anti-TUJ-1) (1:2,000 dilution; Covance research products, Berkeley, California,

\section{Figure 2}

Distribution of SCF in the injured forebrain. (A-G) Sections were immunostained with an $A b$ against SCF and were visualized with DAB (brown). Counterstaining was done with hematoxylin (blue). (A) In the normal cortex, SCF-positive cells exist mainly in the surface of the cortex, in layers I and II. (B) In the "freeze-injured" forebrain, the distribution of SCF-staining cells include the whole depth of cortex, with intensively SCF-positive cells in the layers III, IV. (C and D) Magnified images of the black boxes in $\mathbf{A}$ and $\mathbf{B}$, respectively. Abundant SCF-staining cells were observed in the injured area indicated by arrows in $\mathbf{D}$. ( $E$ and $F$ ) SCF expression was also present in the SVZ of injured brain (F) but was not detectable in the control SVZ (E). (G) Large numbers of SCF-staining cells were present around the injury (boxes I and II), while the SCF-positive cells decreased with increasing distance away from the site of injury (boxes III and IV). Bottom row, higher-magnification views $(\times 200)$ of each section as indicated by the arrows. Boxes I-IV are schematic representations of the areas used to quantify cell numbers. Scale bar (shown in A): A and B, $200 \mu \mathrm{m} ; \mathbf{C}-\mathbf{F}, 50$ $\mu \mathrm{m}$; $\mathbf{G}$, main image, $250 \mu \mathrm{m}$, and higher magnifications, $70 \mu \mathrm{m}$. Str, striatum. (H) Quantification of SCF positive cells in boxes I-IV of G. The SCF-positive cells are presented as a percentage of the total cell number for each section. Comparisons are corrected for surface area and total cells in the section. Statistical differences were determined by comparison of boxes III and IV with box I ( $\left.{ }^{\star} P<0.05\right)$.
USA); biotinylated lectin ricinus communis agglutinin I (RCA I) (1:1,000 dilution, Vector Laboratories, Burlingame, California, USA); and rabbit polyclonal anti-phosphorylated histone H3 (anti-phospho-histone H3) (1:200 dilution; Upstate Biotechnology, Lake Placid, New York, USA). In order to prevent nonspecific binding of antibodies, cells or sections were treated with $5 \%$ normal goat serum in PBS with $0.1 \%$ BSA. The specificity of immunolabeling was verified in all experiments by controls in which the primary antibody was omitted. Secondary antibodies tagged with Alexa Fluor 488 and 594 (Molecular Probes, Eugene, Oregon, USA) were used for visualization at a dilution of 1:500 for each. For dual and triple staining, the primary antibodies used in one section were from different species and single-antibody staining was performed to ensure specificity of staining. Specimens were examined on Zeiss LSM 510 confocal imaging system (Zeiss, Heidelberg, Germany) for immunofluorescence. Individual optical sections (optical depth, less than $0.1 \mu \mathrm{m}$ ) were obtained for different fluorogens
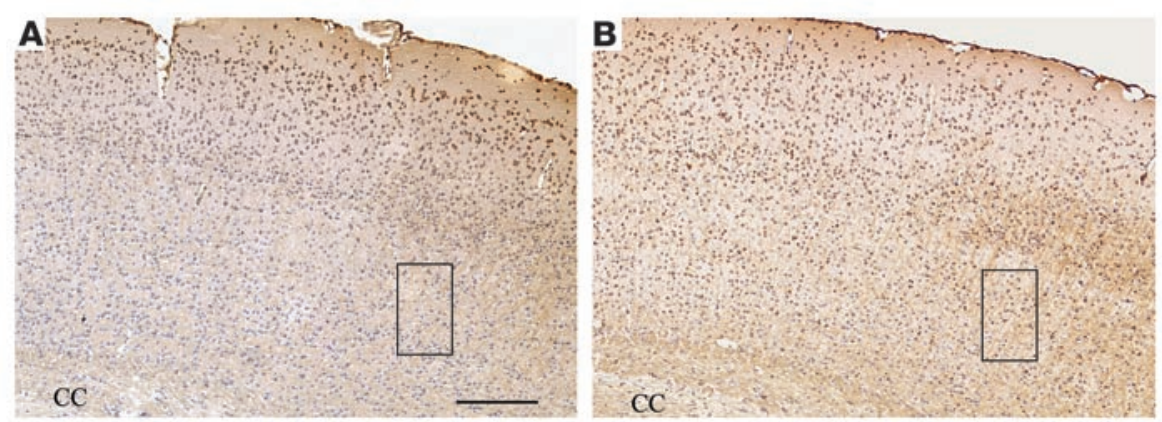

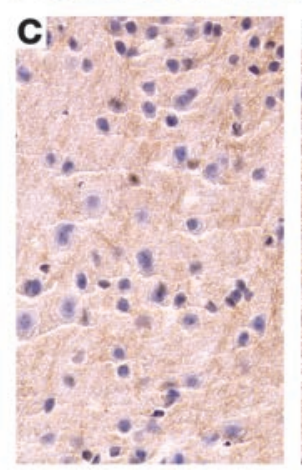

G
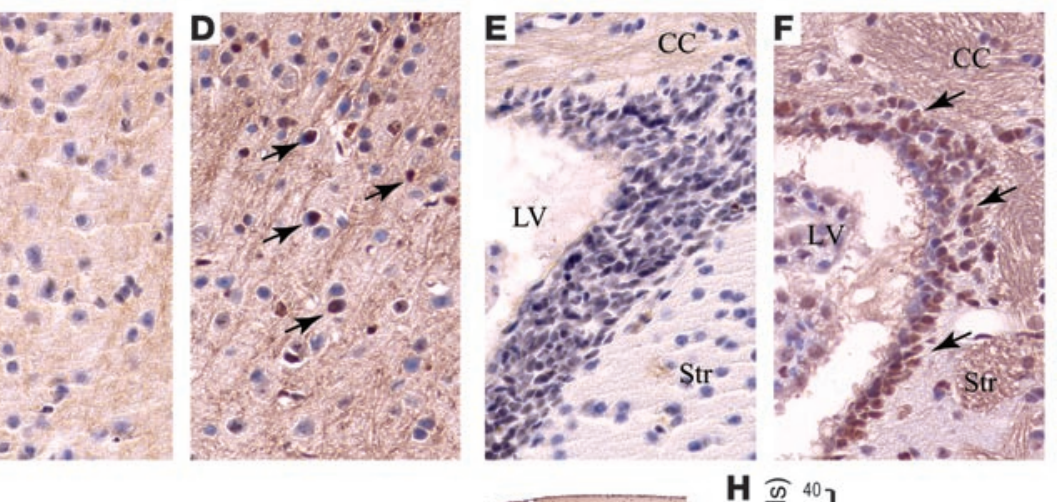

H

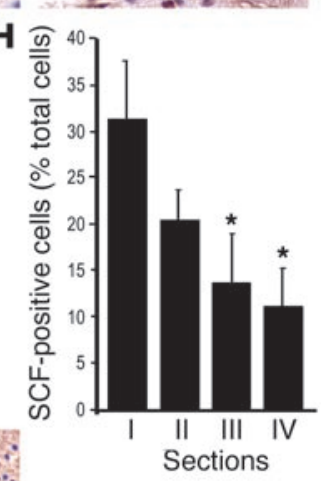



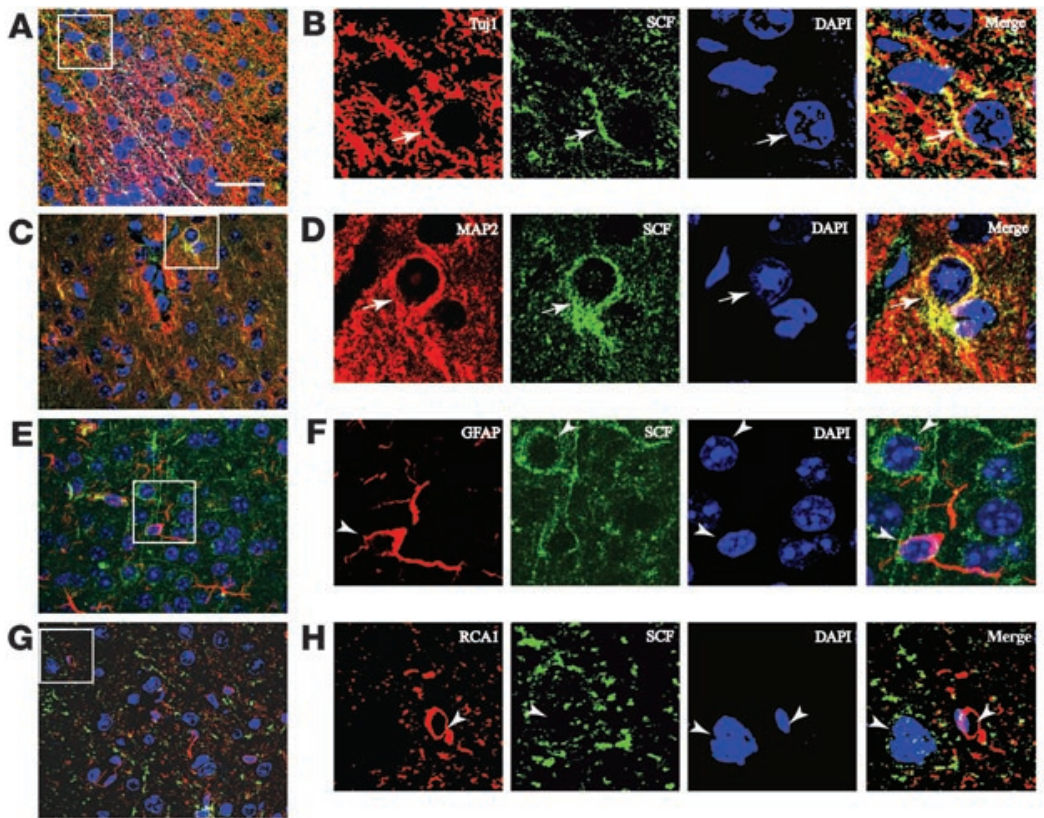

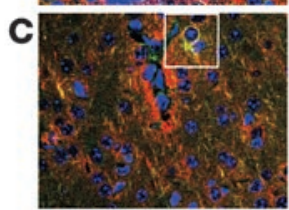

\section{Figure 3}

Characterization of SCF-positive cells in the cortex 7 days after injury. (A-H) Sections were double immunostained for TUJ-1 and SCF (A and B), MAP2 and SCF ( $\mathbf{C}$ and $\mathbf{D}$ ), GFAP and SCF ( $\mathbf{E}$ and $\mathbf{F}$ ), or lectin RCA I and SCF ( $\mathbf{G}$ and $\mathbf{H}$ ). White boxes in $\mathbf{A}, \mathbf{C}, \mathbf{E}$, and $\mathbf{G}$ are magnified in $\mathbf{B}, \mathbf{D}, \mathbf{F}$, and $\mathbf{H}$, respectively. The enlarged images show double staining for TUJ-1 and SCF or MAP2 and SCF (arrows), and GFAP, RCA I or SCF single-positive cells (arrowheads). Scale bar (shown in A): A, C, E, and $\mathbf{G}, 50 \mu \mathrm{m} ; \mathbf{B}, \mathbf{D}$, and $\mathbf{H}$, $16 \mu \mathrm{m} ; \mathbf{F}, 18 \mu \mathrm{m}$.

were identified. The microarray membranes, which contained the individual clones from the SSH library in duplicate, were hybridized with cDNA from injured frontal lobe or with cDNAs from the uninjured contralateral side. The differentially expressed clones were subsequently sequenced and two of them were identified as SCF (Figure 1B). The injury-mediated induction of SCF mRNA expression was further confirmed by quantitative real-

and stacked optical sections were merged using Maximum Projection Software (Zeiss). For quantitative immunocytochemical data, Abercrombe's correction was used to approximate the number of cells with positive staining per examined area and a percentage per total cells within the area. Data were expressed as means \pm SEM.

BrdU labeling and intracerebral stereotactic injections. For labeling of neural progenitors in vivo, BrdU (Roche) was administrated intraperitoneally twice a day, at 8-hour intervals, for 14 days (50 $\mathrm{mg} / \mathrm{kg}$ body weight). Twenty hours after the last BrdU injection, several animals were killed and their brains were sectioned for BrdU immunostaining. Intracerebral injections were administered to the remaining animals. Stereotactic surgery was performed as described for the "freeze" injury, and injections were given at the position of 1 $\mathrm{mm}$ anterior to the bregma, $1.5 \mathrm{~mm}$ lateral to the midline, and 2.5 $\mathrm{mm}$ ventral to the dura. Mice received a suspension of $\operatorname{rmSCF}(3 \mu \mathrm{g}$ in $3 \mu$ l of PBS; R\&D Systems) or PBS through a Hamilton syringe. Each injection took 15 minutes. Seven days after the intracranial injection, the animals were killed and their brains were processed for BrdU immunohistochemical analysis. For ventricular injection of DiI (1,1'-dioctadecyl-6,6'-di(4-sulfophenyl)-3,3,3',3'-tetrametylindocarbocyanine; Molecular Probes) or adenovirus expressing GFP, $2 \mu \mathrm{l}$ of $0.2 \% \mathrm{DiI}$ in DMSO or $2 \mu \mathrm{l}$ of replication-incompetent adenovirus $\left(10^{8}\right.$ plaque-forming units per microliter) (36) was injected $0.5 \mathrm{~mm}$ posterior and $0.7 \mathrm{~mm}$ lateral to bregma, and $2 \mathrm{~mm}$ below the dura matter, into the lateral ventricle. Three days after ventricular injection, SCF was injected into the left hemisphere as described above. Seven days after SCF injection, the brains were sectioned and analyzed for DiI or GFP distribution.

\section{Results}

SCF expression induced by "freeze" injury in brain. "Freeze" injuries were introduced into the right frontal lobe of mouse brain as illustrated in Figure 1A. Genes that were differentially expressed in brain tissue 5 days after injury were globally screened through $\mathrm{SSH}$ using contralateral uninjured tissue as a control. The differential expression of the isolated clones was verified using custom microarray. More than 300 clones, representing 196 unique genes, time RT-PCR, revealing an increase of more than twofold in SCF transcripts in the injured tissue (Figure 1C).

We next investigated whether SCF protein, in parallel to SCF mRNA, was also increased in the injured brain. Western blot confirmed the presence of two SCF bands corresponding to the transmembrane and cleaved soluble forms of SCF (33 and $19 \mathrm{kDa}$, respectively; Figure 1D). Compared with that of the corresponding forebrain tissue of uninjured mice, SCF protein levels increased as early as day 1 after injury, with the soluble form reaching maximum induction by day 5 and the membrane-bound form peaking 7 days after injury. The total amount of SCF also peaked at day 7 and then declined by day 12 after injury (Figure 1E). Finally, we analyzed the distribution of SCF protein in the injured forebrain. SCF immunohistochemical staining was barely detectable in the uninjured control forebrains and was only weakly detectable in cortical layers I and II (Figure 2, A and C). In contrast, prominent staining was seen in cells in layers II, III, IV, and V of the injured neocortex, with extension up to the corpus callosum (Figure 2, B and D). SCF staining was also observed in the SVZ of injured brain but was not seen in the control brain (Figure 2, E and F). In the contralateral, uninjured hemisphere, we observed some SCF staining in the SVZ and neocortex that was adjacent to the injured side. We did not, however, observe increased SCF expression in the areas of the contralateral uninjured brain at a distance from the site of injury (data not shown). At a microscopic level it was apparent that the highest level of SCF expression occurred in cells immediately adjacent to the site of direct injury, with a slow drop off in the level of expression as the distance increased away from the injury site (Figure 2, G and H). We initially expected that the majority of the SCF would originate from inflammatory cells, specifically bloodborne monocytes and or microglia; however, only a minority of the SCF-expressing cells within the injured brains showed positive staining for microglia and monocytes markers, including lectinRCA I, F4/80, and CD13 (Figure 3, G and H, and data not shown). Likewise, the majority of GFAP-positive cells did not express SCF (Figure 3, E and F). Instead there was intense SCF staining of the neuropil, suggesting a predominantly neuronal expression of SCF. 
Immunohistochemical studies confirmed that the majority of SCF-expressing cells were positive for TUJ-1 and/or MAP2, consistent with neuronal SCF expression (Figure 3, A-D).

Expression of c-kit on the NSPCs and responsiveness to SCF. Human fetal and mouse NSPC populations from embryonic day 14.5 were expanded in serum-free media containing bFGF and EGF. These undifferentiated brain-derived NSPCs grew in neurospheres under our experimental conditions and avidly expressed nestin, a marker for NSPCs. In contrast, the cells showed negative staining for endothelia and mesenchymal differentiation markers (data not shown). The true NSPC-like nature of our cells was confirmed by exposure of the cells to differentiating conditions, which resulted in expression of TUJ-1, GFAP, and CNPase in cells with morphologies consistent with those of neuronal, astrocytic, and oligodendrocytic lineages, respectively (data not shown).

To more directly address the potential effect of SCF on neural progenitor migration, we examined c-kit (SCF receptor) expression and activation on the mouse NSPCs as well as human NSPCs. Semiquantitative RT-PCR revealed abundant $c$-kit mRNA in the cultured mouse and human NSPCs (Figure 4A). Immunohistochemistry confirmed the expression of c-kit receptor in the cultured mouse and human NSPCs (Figure 4, B and C). In addition, we could readily identify a subpopulation of nestinpositive cells in the SVZ that were c-kit positive (Figure 4, D and E), indicating c-kit expression on adult neural progenitors in vivo.

The binding of SCF to its receptor, c-kit, is known to induce c-kit autophosphorylation on tyrosine residues, resulting in activation of various downstream signaling pathways. In order to evaluate whether the c-kit receptor was functional on neural progenitor cells, we stimulated the NSPCs with $100 \mathrm{ng} / \mathrm{ml}$ of rmSCF followed by immunoprecipitation of cellular proteins using a c-kit Ab. Immunoprecipitated proteins were then immunoblotted with a phosphotyrosine $\mathrm{Ab}$ followed by reprobing of the blot with a c-kit $\mathrm{Ab}$, as described in Methods. The results demonstrated that c-kit proteins on NSPCs were strongly phosphorylated after SCF stimulation. Moreover, pretreatment of mouse NSPCs with a specific c-kit-blocking Ab (ACK 45) markedly decreased c-kit autophosphorylation on mouse NSPCs (Figure 5A). These data demonstrate that the c-kit receptor is biologically active, as determined by tyrosine kinase activity, on neural progenitor cells.

Chemoattractant effects of SCF on NSPC migration in vitro. We next asked if the SCF upregulation in the injured brain was functionally relevant for neural progenitor migration. We established a Boyden chamber-based migration assay to quantitatively evaluate NSPC migration in vitro. Lysates from injured brains induced significantly more cell migration than did lysates from normal brains. Additionally, the increased cell migration seen after exposure of NSPCs to injured brain lysates could be abolished by pretreatment of the NSPCs with the ACK45 c-kit-blocking Ab (Figure 5B). This migration inhibition did not occur after pretreatment with a control rat IgG (data not shown).

To directly evaluate the chemoattractant effects of SCF on neural stem cell migration, we used various concentrations $(5-500 \mathrm{ng} / \mathrm{ml})$ of purified rmSCF to induce NSPC migration in the Boyden chamber migration assay. We observed that c-kit mRNA was not detectable in the NIH 3T3 cells by RT-PCR (Figure 4A), and therefore we included NIH 3 T3 cells in the Boyden chamber assay as a negative control. In the presence of $1 \%$ serum, NSPCs and NIH 3 T3 cells demonstrated the same minimal nonspecific migratory response. The response to rmSCF, however, was quite different between
A
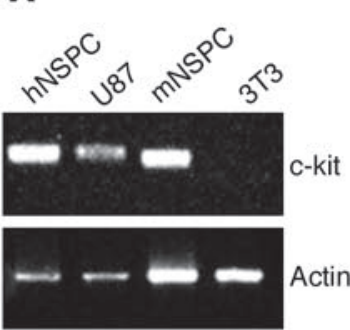

B
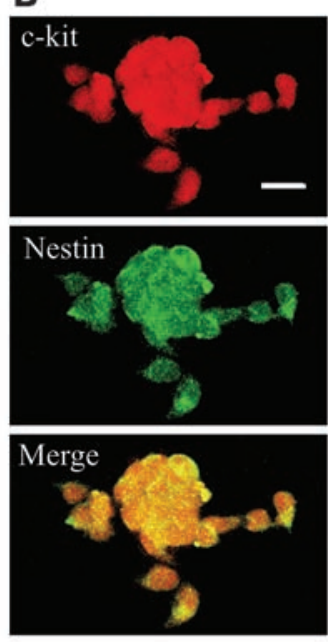

\section{C}
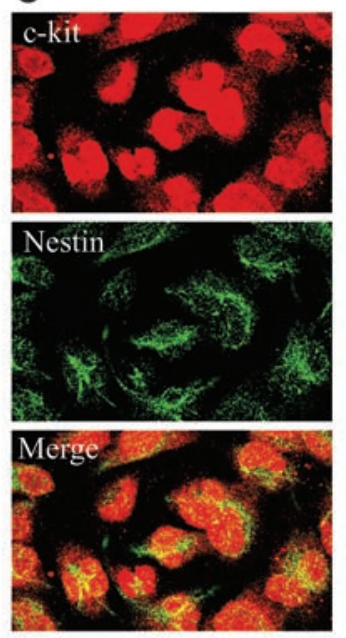

D
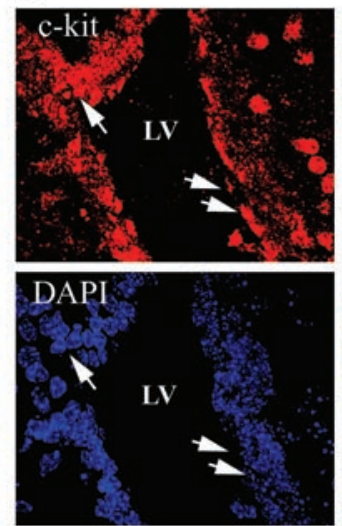

E

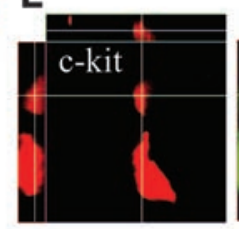

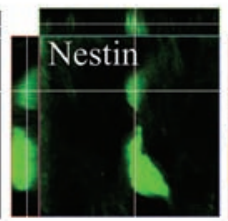
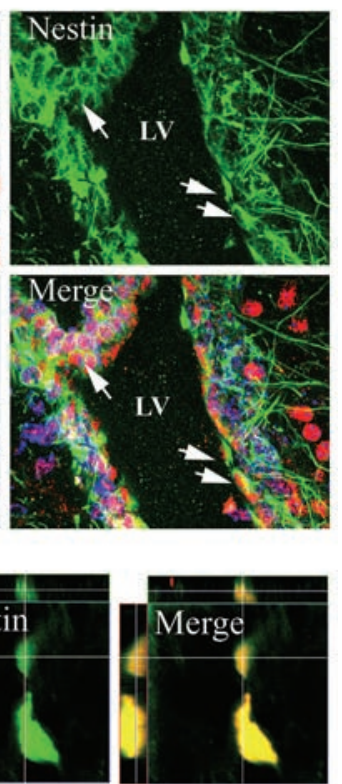

Figure 4

Expression of c-kit in NSPCs in vitro and in vivo. (A) Expression of c-kit mRNA in human NSPCs (hNSPC) and mouse NSPCs (mNSPC), as measured by semiquantitative RT-PCR. (B and C) Immunofluorescence analysis for c-kit and nestin in mouse (B) and human (C) NSPCs. (D and E) Expression of c-kit in NSPCs in vivo. (D) Double staining of mouse brain by c-kit and nestin revealed c-kit expression in nestin-positive cells (arrows) in the SVZ. (E) Representative orthogonal images of colocalization of c-kit and nestin in vivo. Upper, main, and left panels show views of the $x z, x y$, and $y z$ planes, respectively. Lines represent coordinates in each plane. $x$ axis, $24.4 \mu \mathrm{m} ; y$ axis, $24.4 \mu \mathrm{m} ; z$ axis, $6.7 \mu \mathrm{m}$; optical section thickness, $0.02 \mu \mathrm{m}$. Scale bar (shown in B): B-D, $20 \mu \mathrm{m}$. 
A
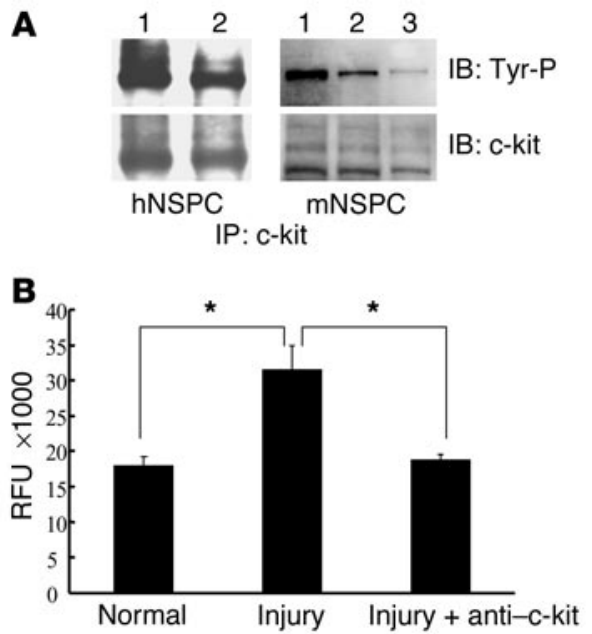

these cell types; rmSCF did not induce migration of NIH 3T3 cells regardless of the concentration used. In contrast, rmSCF resulted a significant chemoattractant effect on NSPCs in a dose-dependent manner (Figure 6). Statistically significant increases in cell migration were seen at SCF concentrations as low as $5 \mathrm{ng} / \mathrm{ml}$ for mouse NSPCs and at $10 \mathrm{ng} / \mathrm{ml}$ for human NSPCs. This experiment was repeated three times and similar results were obtained. These data demonstrate that SCF regulates NSPC migration in vitro.

Chemoattractant effects of SCF on neural stem cell migration in vivo. To test the effects of SCF on endogenous progenitor cell migration in vivo, we prelabeled endogenous dividing NSPCs with BrdU in SCID mice. Twenty hours after the last BrdU injection, several brains were processed for BrdU immunohistochemistry analysis as a day- 0 control. The remaining animals were divided into two groups: those with intracerebral injection of rmSCF and those injected with the vehicle control (PBS). Treated animals were euthanized on day 7 after SCF or PBS administration. The brain sections were then evaluated for expression of $\mathrm{BrdU}$, nestin, and phospho-histone $\mathrm{H} 3$ by immunohistochemistry and fluorescence confocal microscopy. The SCF-treated group had significant numbers of BrdU-positive cells in the SCF-injected area compared with both the contralateral side of the same brain and the PBS-injected brains (Figure 7, A and B). There were approximately twice the number of BrdU-positive cells in the SCF-injected area $\left(1.5-\mathrm{mm}^{2}\right.$ section) compared with the contralateral side and 2.3 times the number of cells in the injected area in SCF-treated animals compared with PBS-treated animals $(P<0.01)$. In contrast, in the day- 0 group animals, the majority of dividing cells were distributed within the SVZ, with only a few cells widely dispersed within the corpus callosum, cerebral cortex, and striatum (Figure 7D). Moreover, BrdU incorporation colocalized with the cell proliferation marker phospho-histone $\mathrm{H} 3$, demonstrating that BrdU incorporation was a function of cell division rather than DNA damage (Figure 7, $\mathrm{D}-\mathrm{F})$. The majority of BrdU-positive cells expressed nestin, indicating that they were NSPCs (Figure 7, G and H).

To clearly demonstrate that the BrdU-positive stem cells were SVZ stem cells that had migrated to the SCF injection site, rather than representing the proliferation of a local population of stem cells, we injected DiI fluorescent dye or adenovirus expressing GFP into the cerebral ventricle of the mouse. As has been previously demonstrated (37), ventricular injection of DiI or GFP adenovirus

\section{Figure 5}

SCF/c-kit pathway is involved in injury-induced NSPC migration. (A) SCF-induced c-kit tyrosine phosphorylation (Tyr-P) was detected by immunoprecipitation (IP) and immunoblot (IB). The 120-kDa and $140-\mathrm{kDa}$ bands represent the c-kit proteins in the human and mouse NSPCs. Lane 1, SCF treatment; lane 2, untreated control; lane 3, pretreatment of NSPCs with ACK45 c-kit-blocking Ab before SCF treatment. (B) Tissue lysates from injured and normal mouse forebrain were used to stimulate migration of mouse NSPCs (with or without pretreatment with $\mathrm{ACK} 45$ blocking $\mathrm{Ab}$ ) in the Boyden chamber migration assay. Relative fluorescence units (RFU) correlated with the number of migrated cells. NSPC migration was significantly induced by injured brain lysates compared with normal brain lysates $\left({ }^{*} P<0.05\right)$. The chemotactic effect of injured brain lysates was nearly completely abolished when NSPCs were pretreated with the c-kit-blocking Ab $\left.{ }^{\star} P<0.05\right)$. Error bars represent SEM. These are representative experiments and similar results were obtained from at least three independent experiments.

enables one to track the progeny of NSPCs in the SVZ region. The ventricular injection of DiI or adenovirus expressing GFP was given prior to SCF administration. The injected DiI was restricted to areas near ventricular zones (Figure 8A), eliminating the possibility of diffusion of free dye into other areas of the brain, thereby ensuring the labeling of cells that were immediately adjacent to the ventricle (Figure 8B). After injection of SCF, significant numbers of DiI-labeled cells were found near the injection site of SCF. In contrast, few DiI-labeled cells were detected in the contralateral cortex of SCF-injected animals or near the injection site in animals injected with PBS (Figure 8, C and D). Similarly, GFP expression was initially confined to cells immediately adjacent to the ventricular system after injection of GFP-expressing adenoviral vectors into the ventricles (Figure 8E). After SCF injection, however, a large number of GFP-positive cells had migrated into the SCF-injected cortex (Figure 8, F and G). Taken together, these ventricular labeling experiments clearly show that SVZ stem cells migrate into the SCF-injected cortex.

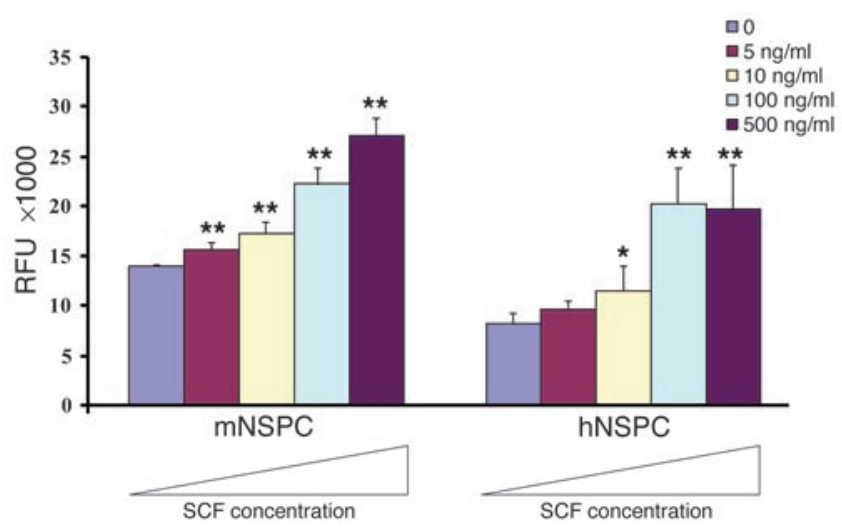

Figure 6

Effects of rmSCF on NSPC migration in the Boyden chamber migration assay. Mouse and human NSPC migration was stimulated in a dose-dependent manner by soluble rmSCF. Error bars represent SEM. ${ }^{*} P<0.05$, and ${ }^{* *} P<0.001$, respectively. $n=3$. This is a representative experiment; similar results were obtained from three independent experiments. 


\section{Discussion}

NSPCs have notable migratory abilities within the CNS under physiological and pathological conditions such as during embryonic nervous system development, adult neurogenesis, and injury response. Although there is a growing body of literature regarding the mechanisms responsible for NSPC migration during CNS development, little is known of the mechanisms that are operative in mediating NSPC migration during times of injury. Understanding of the signals responsible for NSPC migration to sites of brain and spinal cord injury could prove crucial for the development of strategies for NSPC-mediated repair of such damage.

To begin to elucidate the signals involved in NSPC migration to sites of CNS injury, we constructed a "subtraction library" of injured brain tissue compared with control brain tissue. We identified more than 300 clones representing 196 unique genes that are differentially expressed in the injured tissue. In order to prioritize clones that might be most interesting to evaluate first, we made the assumption that a neural progenitor chemoattractant would likely be a membrane-bound and/or secreted protein with the ability to diffuse within the extracellular space of the brain, given the pronounced effect of injury on NSPC migration at relatively large distances. Thus, we performed a bioinformatics screen of our clones, looking for genes that contained a predicted signal peptide. One of the most prominent clones represented in our subtraction and bioinformatics screen was that encoding SCF. Our data demonstrate that SCF mRNA is overexpressed in injured brain compared with normal brain by SSH analysis, custom cDNA microarray analysis, and real-time quantitative RT-PCR. Correspondingly, SCF protein is also induced by injury.

A single SCF gene that maps to $12 \mathrm{q} 22-24$ encodes two different isoforms of the protein $(38,39)$. A longer, 248 -amino acid SCF isoform contains a proteolytic cleavage site at Ala 165 that, after cleavage, results in loss of the transmembrane region and a soluble truncated protein $(40,41)$. Both SCF isoforms bind and activate the c-kit receptor, although their effects on c-kit signaling may be subtly different secondary to differences in receptor internaliza-
A

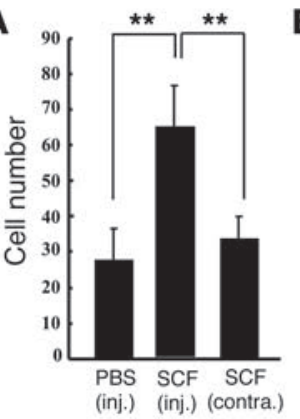

C

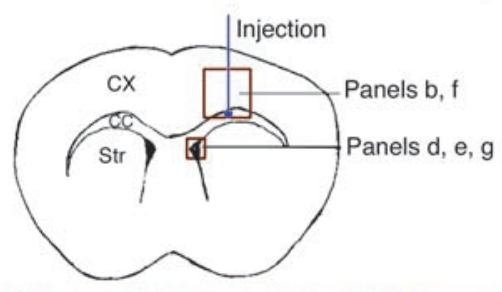

E

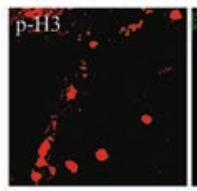

$\mathbf{F}$
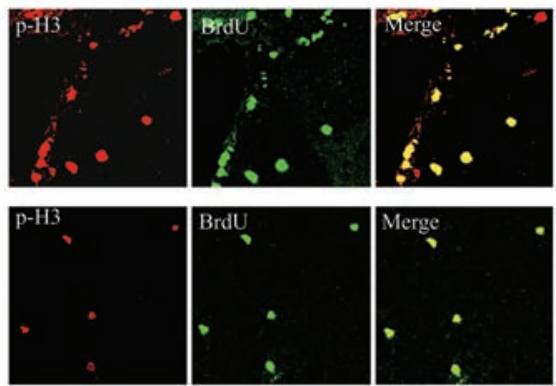

B

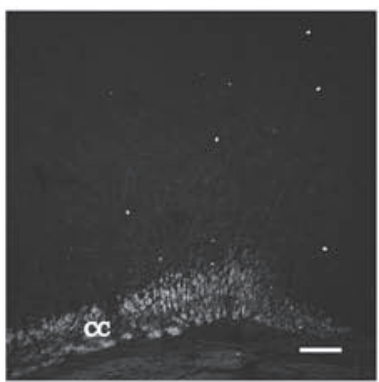

PBS (inj.)

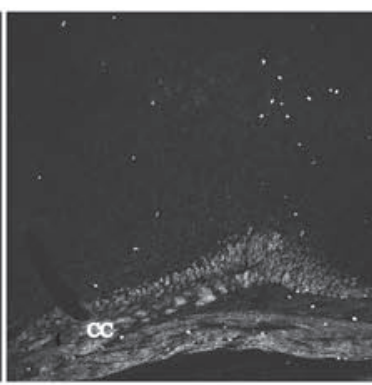

SCF (inj.)

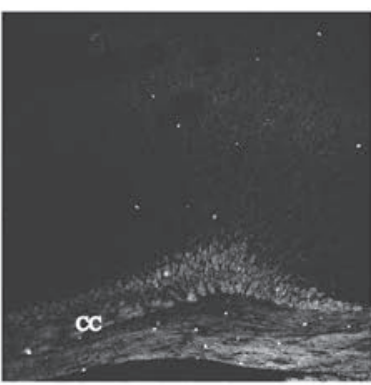

SCF (contra.)

D
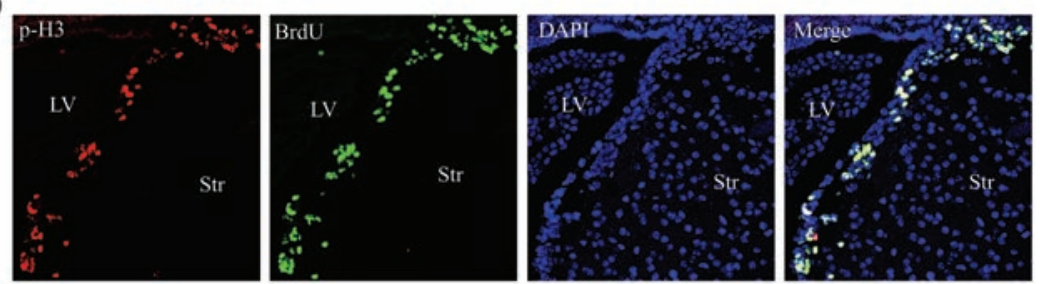

G

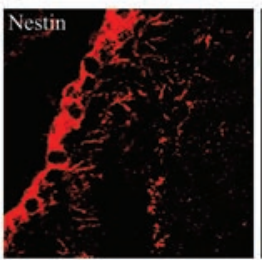

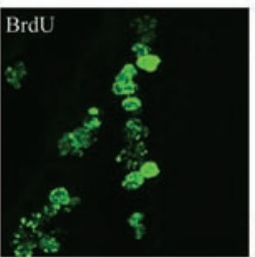

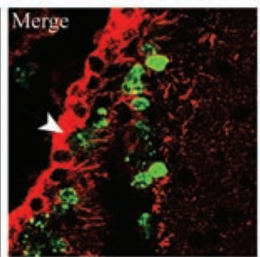

H

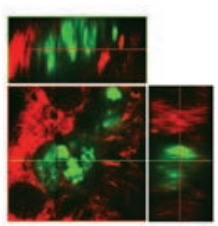

Figure 7

SCF-stimulated progenitor cell migration in vivo. (A) Quantification of BrdU-labeled cells in the injected areas (1.5 $\left.\mathrm{mm}^{2}\right)$ and in the contralateral side of the brain. Significantly more BrdU-labeled cells were seen in the SCF-injected area than in the PBS-injected area or in the contralateral side of the SCF-injected brain $(P<0.001 ; n=6)$. inj., injection side; contra., side contralateral to SCF injection. (B) Representative images of BrdU staining in the cortical areas. (C) Schematic diagram of the brain used to examine the response of NPSC to rmSCF is shown. The blue arrow indicates the intracerebral injection track (as described in Methods). (D) Normal distribution of BrdU-positive cells. These cells were detected mainly in the SVZ prior to SCF injection and were also positive for phospho-histone H3 staining (p-H3). (E and F) Immunohistochemistry of SCF-injected brain with BrdU and phospho-histone H3 antibodies in LVZ (E) and SCF-injected cortex (F). (G) Nestin expression of BrdU-positive cells in the SVZ. (H) Three-dimensional digital image of the cells indicated by the arrowhead in $\mathbf{G}$ is shown. Upper, main, and right panels show views of the $x z, x y$, and $y z$ planes, respectively. Lines represent coordinates in each plane. $x$ axis, $23.2 \mu \mathrm{m} ; y$ axis, $23.2 \mu \mathrm{m} ; z$ axis, $11 \mu \mathrm{m}$; optical section thickness, $1.1 \mu \mathrm{m}$. Scale bar (shown in B): B, $100 \mu \mathrm{m} ; \mathbf{D}, 64 \mu \mathrm{m} ; \mathbf{E}$ and F, $32 \mu \mathrm{m} ; \mathrm{G}, 12 \mu \mathrm{m}$. 


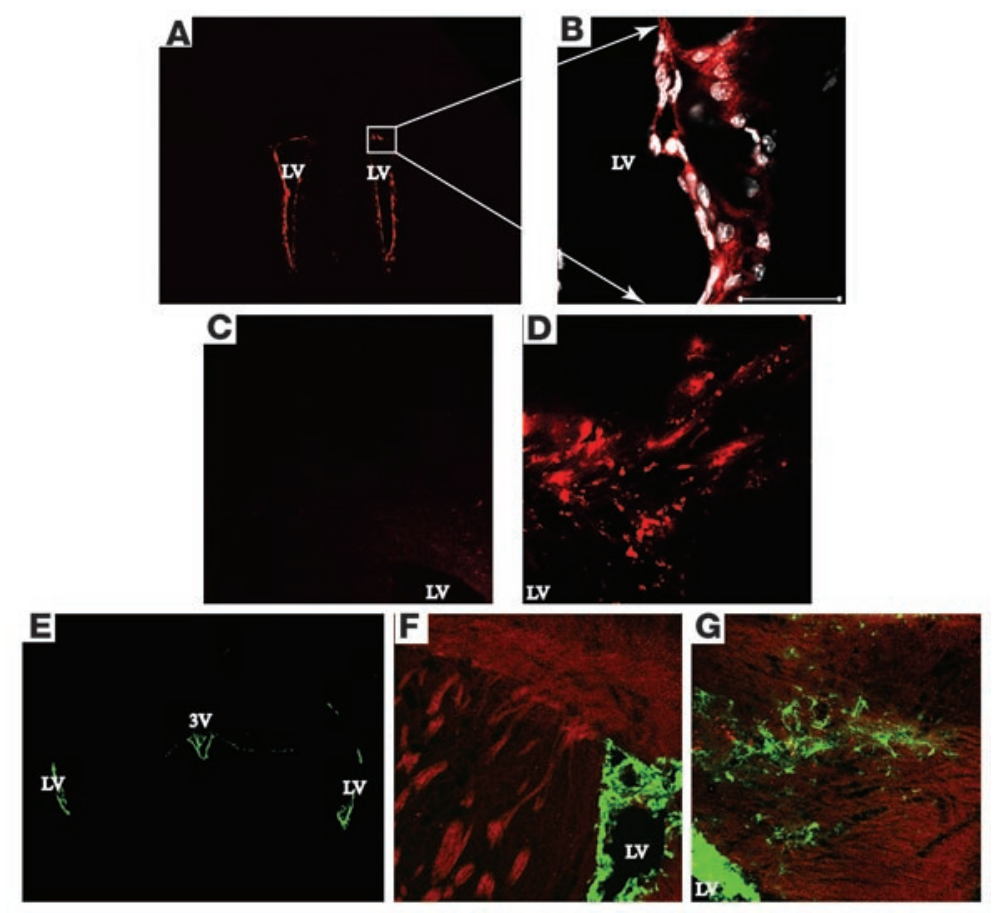

\section{Figure 8}

SCF-stimulated progenitor cell migration in vivo. (A and $\mathbf{B}$ ) Whole-brain image of Dil labeling after ventricular injection of Dil. Dil-labeled cells (red) were only detected in the lining of ventricular zone. Boxed regions in $\mathbf{A}$ are shown at higher magnification in $\mathbf{B}$. Dil staining was confined to the nuclei and process of cells. (C and D) Representative images of control hemisphere (C) and SCF-injected hemisphere (C). Note the greater number of Dil-positive cells in the SCF injection side. (E) Whole-brain image of GFP-positive cells (green) in the brain. 3V, third ventricle. (F and $\mathbf{G}$ ) Representative images of control hemisphere $(\mathbf{F})$ and SCF-injected hemisphere (G). Scale bar (shown in B): $\mathbf{A}$ and $\mathbf{E}, 100 \mu \mathrm{m}$; B-D, F, and G, $20 \mu \mathrm{m}$. tion (42). Specifically, the soluble c-kit/SCF complex is rapidly internalized and degraded, resulting in transient tyrosine kinase activation of c-kit, whereas the membrane-bound SCF appears to prevent receptor internalization, resulting in more persistent receptor tyrosine phosphorylation (43-45). Loss-of-function mutations in SCF or c-kit have demonstrated the importance of the SCF/c-kit pathway in hematopoiesis, gametogenesis, and melanogenesis. In contrast, activating mutations in c-kit mediate transformation of hematopoietic stem cells, mast cells, and gastrointestinal stromal cells (46-51). Recent reports have indicated that the SCF/c-kit pathway is activated during injury and plays a protective role in selected injury models of non-neural tissue $(52,53)$. In addition to these effects on cellular proliferation, differentiation, survival, and transformation, SCF can also induce migration of hematopoietic stem cells, melanoblasts, and mast cells (54-60).

Our data are consistent with a previous report demonstrating that SCF expression is induced by brain injury in neurons surrounding the injury, as assessed by in situ hybridization and immunohistochemistry (61). Additionally, a recent study has shown increased SCF levels in the medium from cerebral cortical cultures after hypoxic insult, suggesting that SCF is also induced in other types of neural injury such as cerebral ischemia (62). We have now extended these observations by demonstrating not only that SCF is overexpressed in neurons after traumatic injury in vivo but also that recombinant SCF can directly induce neural stem cell migration in vitro and in vivo. These data, therefore, suggest a role for SCF in mediating NSPC migration to areas of acute brain injury. Of interest is a previous report suggesting that the brain predominantly produces the soluble form of SCF (63). Our Western blot data, however, clearly demonstrate that although the soluble form of SCF is predominant, membrane-bound SCF is also increased in the traumatized brain. Given the differences in the degree and kinetics of c-kit activation between the two different SCF isoforms, it is tempting to speculate that the production of both the soluble and membrane forms of the cytokine more readily allows for the establishment of a chemotaxis gradient toward the site of injury.

In addition to demonstrating the direct migratory effects of SCF on NSPCs, we have also demonstrated the presence of c-kit on NSPCs, the resultant tyrosine phosphorylation of the receptor after exposure to SCF, and the presence of activated receptor on progenitor cells in the SVZ of the lateral ventricle and subgranular zone of the hippocampal dentate gyrus. These data are consistent with those of Jin and co-workers, who demonstrated c-kit expression in neuroproliferative zones in the adult mammalian brain after ischemic injury (62). The signal transduction pathways operative in NSPC migration after c-kit activation remain to be fully elucidated, although recent evidence suggests that c-kit-mediated mast cell migration is dependent on phosphoinositide-3 kinase (PI-3Kinase) signaling (64). Recent work has demonstrated that mouse NSPCs heterozygous for phosphatase and tensin homolog deleted on chromosome 10 (PTEN) have increased migratory properties and that conditional PTEN knockout mice have disorganization of brain neuronal architecture, probably due to precursor migratory errors. These data are consistent with a central role for PI-3Kinase in NSPC migration, as PTEN is a negative regulator of components of PI-3Kinase signaling $(64,65)$. Finally, recent data suggest a role for Slug, a member of the Snail zinc-finger family of transcription factors, in SCF-mediated migration of hematopoietic and gamete stem cells (66). Although further studies are clearly needed to precisely define the role of PI-3Kinase and Slug in c-kit-induced NSPC migration, our data clearly demonstrate that the SCF/c-kit pathway is activated within the brain after both traumatic and ischemic injury and contributes to NSPC migration to those sites of injury.

Although both SCF expression in neurons and c-kit activation on NSPCs after injury have been described previously, this is the first report to our knowledge that has made the functional connection between neuronally expressed SCF and induction of NSPC migration to the site of injury. Given the known migratory effects of SCF on other types of stem cell populations, it is perhaps not entirely 
surprising that SCF has such effects on NSPCs. We do not at this time understand the significance of injury-induced SCF-mediated neural stem cell migration to sites of injury, although it is tempting to speculate that recruitment of NSPCs is part of an injury repair process. Whether SCF/c-kit-mediated recruitment of NSPCs to sites of injury actually accomplishes this goal, what other molecules are operative in this process, and whether SCF is playing an additional role in injury-induced neurogenesis and stem cell differentiation within the area of injury are important questions that will require additional study. Irrespective of the physiological role of SCF in the brain, the elucidation of SCF as a potent NSPC migratory factor opens up an opportunity to utilize recombinant or genetic vectorderived SCF as a chemotactic agent to induce NSPC recruitment to specific areas of the CNS for cell-based therapeutic interventions.

\section{Acknowledgments}

The authors thank Jim Nagle and Deborah Kauffman of the National Institute of Neurological Disorders and Stroke sequencing facility for technical support in DNA sequencing.

Received for publication September 9, 2003, and accepted in revised form February 17, 2004.

Address correspondence: Howard A. Fine, Neuro-Oncology Branch, National Cancer Institute, National Institutes of Neurological Disorder and Stroke, NIH, The Block Building, Room 225, 9030 Old Georgetown Road, Bethesda, Maryland 208928200, USA. Phone: (301) 402-6383; Fax: (301) 480-2246; E-mail: hfine@mail.nih.gov.
1. Gage, F.H. 2002. Neurogenesis in the adult brain. J. Neurosci. 22:612-613.

2. Alvarez-Buylla, A., and Lois, C. 1995. Neuronal stem cells in the brain of adult vertebrates. Stem Cells. 13:263-272.

3. Hatten, M.E. 1999. Central nervous system neuronal migration. Annu. Rev. Neurosci. 22:511-539.

4. Lois, C., Garcia-Verdugo, J.M., and Alvarez-Buylla, A. 1996. Chain migration of neuronal precursors. Science. 271:978-981.

5. Bedard, A., Levesque, M., Bernier, P.J., and Parent, A. 2002. The rostral migratory stream in adult squirrel monkeys: contribution of new neurons to the olfactory tubercle and involvement of the antiapoptotic protein Bcl-2. Eur. J. Neurosci. 16:1917-1924.

6. Fukushima, N., Yokouchi, K., Kawagishi, K., and Moriizumi, T. 2002. Differential neurogenesis and gliogenesis by local and migrating neural stem cells in the olfactory bulb. Neurosci. Res. 44:467-473.

7. Arvidsson, A., Collin, T., Kirik, D., Kokaia, Z., and Lindvall, O. 2002. Neuronal replacement from endogenous precursors in the adult brain after stroke. Nat. Med. 8:963-970

8. Parent, J.M., Valentin, V.V., and Lowenstein, D.H. 2002. Prolonged seizures increase proliferating neuroblasts in the adult rat subventricular zoneolfactory bulb pathway. J. Neurosci. 22:3174-3188.

9. Iwai, M., et al. 2003. Temporal profile of stem cell division, migration, and differentiation from subventricular zone to olfactory bulb after transient forebrain ischemia in gerbils. J. Cereb. Blood Flow Metab. 23:331-341.

10. Fricker, R.A., et al. 1999. Site-specific migration and neuronal differentiation of human neural progenitor cells after transplantation in the adult rat brain. J. Neurosci. 19:5990-6005.

11. Aboody, K.S., et al. 2000. From the cover: Neural stem cells display extensive tropism for pathology in adult brain: Evidence from intracranial gliomas. Proc. Natl. Acad. Sci. U. S. A. 97:12846-12851.

12. Li, Z., et al. 2002. Cell dynamics of calretininimmunoreactive neurons in the rostral migratory stream after ibotenate-induced lesions in the forebrain. Neurosci. Res. 42:123-132.

13. Ehtesham, M., et al. 2002. Induction of glioblastoma apoptosis using neural stem cell-mediated delivery of tumor necrosis factor-related apoptosis-inducing ligand. Cancer Res. 62:7170-7174.

14. Yip, S., et al. 2003. Neural stem cell biology may be well suited for improving brain tumor therapies. Cancer J. 9:189-204.

15. Luskin, M.B. 1993. Restricted proliferation and migration of postnatally generated neurons derived from the forebrain subventricular zone. Neuron. 11:173-189.

16. Becker, P.S., et al. 1999. Adhesion receptor expression by hematopoietic cell lines and murine progenitors: modulation by cytokines and cell cycle status. Exp. Hematol. 27:533-541.

17. Song, H., and Poo, M. 2001. The cell biology of neuronal navigation. Nat. Cell Biol. 3:E81-E88.

18. Serafini, T., et al. 1994. The netrins define a family of axon outgrowth-promoting proteins homologous to C. elegans UNC-6. Cell. 78:409-424.

19. Yee, K.T., Simon, H.H., Tessier-Lavigne, M., and O'Leary, D.M. 1999. Extension of long leading processes and neuronal migration in the mammalian brain directed by the chemoattractant netrin- 1 . Neuron. 24:607-622.

20. Kennedy, T.E., Serafini, T., de la Torre, J.R., and Tessier-Lavigne, M. 1994. Netrins are diffusible chemotropic factors for commissural axons in the embryonic spinal cord. Cell. 78:425-435.

21. Meyerhardt, J.A., et al. 1999. Netrin-1: interaction with deleted in colorectal cancer (DCC) and alterations in brain tumors and neuroblastomas. Cell Growth Differ. 10:35-42.

22. Spassky, N., et al. 2002. Directional guidance of oligodendroglial migration by class 3 semaphorins and netrin-1. J. Neurosci. 22:5992-6004.

23. Bagri, A., and Tessier-Lavigne, M. 2002. Neuropilins as Semaphorin receptors: in vivo functions in neuronal cell migration and axon guidance. $A d v$. Exp. Med. Biol. 515:13-31.

24. Kolodkin, A.L., Matthes, D.J., and Goodman, C.S. 1993. The semaphorin genes encode a family of transmembrane and secreted growth cone guidance molecules. Cell. 75:1389-1399.

25. Smith, A., Robinson, V., Patel, K., and Wilkinson, D.G. 1997. The EphA4 and EphB1 receptor tyrosine kinases and ephrin-B2 ligand regulate targeted migration of branchial neural crest cells. Curr. Biol. 7:561-570.

26. Wang, H.U., and Anderson, D.J. 1997. Eph family transmembrane ligands can mediate repulsive guidance of trunk neural crest migration and motor axon outgrowth. Neuron. 18:383-396.

27. Rothberg, J.M., Jacobs, J.R., Goodman, C.S., and Artavanis-Tsakonas, S. 1990. slit: an extracellular protein necessary for development of midline glia and commissural axon pathways contains both EGF and LRR domains. Genes Dev. 4:2169-2187.

28. Simpson, J.H., Kidd, T., Bland, K.S., and Goodman, C.S. 2000. Short-range and long-range guidance by slit and its Robo receptors. Robo and Robo2 play distinct roles in midline guidance. Neuron. 28:753-766.

29. Wu, W., et al. 1999. Directional guidance of neuronal migration in the olfactory system by the protein Slit. Nature. 400:331-336.

30. Nakatomi, H., et al. 2002. Regeneration of hippocampal pyramidal neurons after ischemic brain injury by recruitment of endogenous neural progenitors. Cell. 110:429-441.

31. Forsberg-Nilsson, K., Behar, T.N., Afrakhte, M., Barker, J.L., and McKay, R.D. 1998. Platelet-derived growth factor induces chemotaxis of neuroepithelial stem cells. J. Neurosci. Res. 53:521-530.

32. Carpenter, M.K., et al. 1999. In vitro expansion of a multipotent population of human neural progenitor cells. Exp. Neurol. 158:265-278.

33. Sun, L., Vitolo, M., and Passaniti, A. 2001. Runtrelated gene 2 in endothelial cells: inducible expression and specific regulation of cell migration and invasion. Cancer Res. 61:4994-5001.

34. Sun, L., Margolis, F.L., Shipley, M.T., and Lidow, M.S. 1998. Identification of a long variant of mRNA encoding the NR3 subunit of the NMDA receptor: its regional distribution and developmental expression in the rat brain. FEBS Lett. 441:392-396.

35. Lee, J., Hampl, M., Albert, P., and Fine, H.A. 2002. Antitumor activity and prolonged expression from a TRAIL-expressing adenoviral vector. Neoplasia. 4:312-323.

36. He, T.C., et al. 1998. A simplified system for generating recombinant adenoviruses. Proc. Natl. Acad. Sci. U. S. A. 95:2509-2514.

37. Clarke, D.L., Risling, M., Lendahl, U., and Frisen, J. 1999. Identification of a neural stem cell in the adult mammalian central nervous system. Cell. 96:25-36.

38. Geissler, E.N., et al. 1991. Stem cell factor (SCF), a novel hematopoietic growth factor and ligand for c-kit tyrosine kinase receptor, maps on human chromosome 12 between $12 \mathrm{q} 14.3$ and 12 qter. Somat. Cell Mol. Genet. 17:207-214.

39. Zsebo, K.M., et al. 1990. Stem cell factor is encoded at the Sl locus of the mouse and is the ligand for the c-kit tyrosine kinase receptor. Cell. 63:213-224.

40. Pandiella, A., Bosenberg, M.W., Huang, E.J., Besmer, P., and Massague, J. 1992. Cleavage of membrane-anchored growth factors involves distinct protease activities regulated through common mechanisms. J. Biol. Chem. 267:24028-24033.

41. Longley, B.J., et al. 1997. Chymase cleavage of stem cell factor yields a bioactive, soluble product. Proc. Natl. Acad. Sci. U. S. A. 94:9017-9021.

42. Jiang, X., et al. 2000. Structure of the active core of human stem cell factor and analysis of binding to its receptor kit. EMBO J. 19:3192-3203.

43. Kurosawa, K., et al. 1996. Immobilized anti-KIT monoclonal antibody induces ligand-independent dimerization and activation of Steel factor receptor: biologic similarity with membrane-bound form of Steel factor rather than its soluble form. Blood. 87:2235-2243.

44. Miyazawa, K., et al. 1995. Membrane-bound Steel factor induces more persistent tyrosine kinase activation and longer life span of c-kit gene-encoded protein than its soluble form. Blood. 85:641-649.

45. Ikuta, K., Ingolia, D.E., Friedman, J., Heimfeld, S., and Weissman, I.L. 1991. Mouse hematopoietic stem cells and the interaction of c-kit receptor and steel factor. Int. J. Cell Cloning. 9:451-460. 
46. Taylor, M.L., et al. 2001. The Kit-activating mutation D816V enhances stem cell factor-dependent chemotaxis. Blood. 98:1195-1199.

47. Galli, S.J., Tsai, M., Gordon, J.R., Geissler, E.N., and Wershil, B.K. 1992. Analyzing mast cell development and function using mice carrying mutations at W/c-kit or Sl/MGF (SCF) loci. Ann. N. Y. Acad. Sci. 664:69-88.

48. Mackenzie, M.A., Jordan, S.A., Budd, P.S., and Jackson, I.J. 1997. Activation of the receptor tyrosine kinase Kit is required for the proliferation of melanoblasts in the mouse embryo. Dev. Biol. 192:99-107.

49. Kunisada, T., et al. 1998. Transgene expression of steel factor in the basal layer of epidermis promotes survival, proliferation, differentiation and migration of melanocyte precursors. Development. 125:2915-2923.

50. Miller, S.C., Fleming, W.H., Zsebo, K.M., and Weissman, I.L. 1993. The in vivo effects of steel factor on natural killer lineage cells in murine spleen and bone marrow. Nat. Immun. 12:293-301.

51. Kunisada, T., et al. 1998. Murine cutaneous mastocytosis and epidermal melanocytosis induced by keratinocyte expression of transgenic stem cell factor. J. Exp. Med. 187:1565-1573.
52. Bone-Larson, C.L., et al. 2000. Novel protective effects of stem cell factor in a murine model of acute septic peritonitis. Dependence on MCP-1. Am. J. Pathol. 157:1177-1186.

53. Simpson, K., et al. 2003. Stem cell factor attenuates liver damage in a murine model of acetaminopheninduced hepatic injury. Lab Invest. 83:199-206.

54. Kim, C.H., and Broxmeyer, H.E. 1998. In vitro behavior of hematopoietic progenitor cells under the influence of chemoattractants: stromal cellderived factor- 1 , steel factor, and the bone marrow environment. Blood. 91:100-110.

55. Meininger, C.J., et al. 1992. The c-kit receptor ligand functions as a mast cell chemoattractant. Blood. 79:958-963.

56. Nilsson, G., Butterfield, J.H., Nilsson, K., and Siegbahn, A. 1994. Stem cell factor is a chemotactic factor for human mast cells. J. Immunol. 153:3717-3723.

57. Gomperts, M., Wylie, C., and Heasman, J. 1994. Primordial germ cell migration. Ciba Found. Symp. 182:121-134

58. Jordan, S.A., and Jackson, I.J. 2000. MGF (KIT ligand) is a chemokinetic factor for melanoblast migration into hair follicles. Dev. Biol. 225:424-436.

59. Klein, A., et al. 2000. Stem cell factor plays a major role in the recruitment of eosinophils in allergic pleurisy in mice via the production of leukotriene B4. J. Immunol. 164:4271-4276.

60. Drayer, A.L., et al. 2000. The in vitro effects of cytokines on expansion and migration of megakaryocyte progenitors. Br. J. Haematol. 109:776-784.

61. Zhang, S.C., and Fedoroff, S. 1999. Expression of stem cell factor and c-kit receptor in neural cells after brain injury. Acta Neuropathol. (Berl) 97:393-398.

62. Jin, K., Mao, X.O., Sun, Y., Xie, L., and Greenberg, D.A. 2002. Stem cell factor stimulates neurogenesis in vitro and in vivo. J. Clin. Invest 110:311-319. doi:10.1172/JCI200215251.

63. Huang, E.J., Nocka, K.H., Buck, J., and Besmer, P. 1992. Differential expression and processing of two cell associated forms of the kit-ligand: KL-1 and KL-2. Mol. Biol. Cell. 3:349-362.

64. Li, L., et al. 2002. PTEN in neural precursor cells: regulation, apoptosis, and proliferation. Mol. Cell. Neurosci. 20:21-29.

65. Li, L., Liu, F., and Ross, A.H. 2003. PTEN regulation of neural development and CNS stem cells. J. Cell. Biochem. 88:24-28.

66. Perez-Losada, J., et al. 2002. Zinc-finger transcription factor Slug contributes to the function of the stem cell factor c-kit signaling pathway. Blood. 100:1274-1286. 